This is the peer-reviewed version of the following article:

W. Li, L. Spada, N. Tasinato, et al. Theory Meets Experiment for Noncovalent Complexes: The Puzzling Case of Pnicogen Interactions. Angew. Chem. Int. Ed., 2018, 57, $13853-13857$.

Which has been published in final form at:

https://doi.org/10.1002/anie.201807751

This article may be used for non-commercial purposes in accordance with Wiley (o Wiley-VCH) Terms and Conditions for Self-Archiving.

(C) 2018 Wiley-VCH Verlag GmbH \& Co. KGaA, Weinheim 


\title{
Theory meets experiment for noncovalent complexes: the puzzling case of pnicogen interactions
}

\author{
Weixing Li ${ }^{[a]}$ Lorenzo Spada, ${ }^{[a],[b],{ }^{*}}$ Nicola Tasinato, ${ }^{[b]},{ }^{*}$ Sergio Rampino, ${ }^{[b]}$ Luca Evangelisti, ${ }^{[a]}$ Andrea \\ Gualandi, ${ }^{[a]}$ Pier Giorgio Cozzi, ${ }^{[a]}$ Sonia Melandri, ${ }^{[a]}$ Vincenzo Barone,${ }^{[b]}$ Cristina Puzzarini ${ }^{[a]},{ }^{*}$
}

Dedication ((optional))

\begin{abstract}
A gas-phase nitrogen-nitrogen noncovalent interaction has been unveiled in the nitroethane-trimethylamine complex, in an environment free from solvent and matrix effects using rotational spectroscopy in supersonic expansion. Different quantum chemical models (NOCV/CD and NBO) agree in indicating that this interaction largely prevails over the $\mathrm{C}-\mathrm{H} \cdots \mathrm{O}$ and $\mathrm{C}-\mathrm{H} \cdots \mathrm{N}$ hydrogen bonds. Furthermore, a SAPT analysis shows that electrostatic and dispersion interactions play a comparable role in stabilizing the complex. The conformational landscape exploration and stationary points characterization have been performed using state-of-the-art quantumchemical computations providing significant insights on structure determination.
\end{abstract}

Noncovalent interactions play a key role in several biological ${ }^{[1]}$ and technological processes, ${ }^{[2-5]}$ yet their characterization and interpretation are still far from being satisfactory, especially when the bonding pair is made up of two non-hydrogen atoms. In this connection, integrated experimental and computational investigations can play an invaluable role provided that the accuracy of the results is accompanied by their rigorous and understandable interpretation. In addition to the well-established hydrogen and halogen bonds, emerging classes of noncovalent interactions are attracting increasing attention, such as the R$\mathrm{X} \cdots \mathrm{Y}$ ones involving a pnicogen atom $(\mathrm{X}=\mathrm{N}, \mathrm{P}, \mathrm{As}, \mathrm{Sb}$ or $\mathrm{Bi}),{ }^{[6]}$ with $X$ and $Y$ being the pnicogen bond donor and acceptor, respectively, in analogy with hydrogen ${ }^{[7]}$ and halogen bond definitions. ${ }^{\left[{ }^{[8]}\right.}$

Several spectroscopic investigations, ranging from NMR to X-ray, and theoretical calculations have been devoted to the description of this kind of noncovalent interactions. Among others, worth of mention are those studies that led to the characterization of heavy pnicogen $\cdots \pi$ interactions ${ }^{[9]}$ and of the $\mathrm{P} \cdots \mathrm{P}^{[10]}, \mathrm{P} \cdots \mathrm{N}^{[11,12]}$ and $\mathrm{P} \cdots \mathrm{O}$ noncovalent bonds. ${ }^{[12]}$ In particular, it has been recently suggested that the last two interactions might play a role in catalytic mechanisms involving phosphorous compounds. ${ }^{[13]}$ Much less information is available in the literature for nitrogen, whose positive electrostatic potential (" $\sigma$ - and $\pi$-holes") ${ }^{[14]}$ is the

[a] Dr. W. Li, Dr. L. Spada, Dr. L. Evangelisti, Dr. A. Gualandi, Prof. Dr. P. G. Cozzi, Prof. Dr. S. Melandri, Prof. Dr. C. Puzzarini Dipartimento di Chimica "Giacomo Ciamician" University of Bologna

Via Selmi 2, 40126 Bologna (Italy)

E-mail: cristina.puzzarini@unibo.it

[b] Dr. L. Spada, Dr. N. Tasinato, Dr. S. Rampino, Prof. Dr. V. Barone Scuola Normale Superiore

Piazza dei Cavalieri 7, 56126 Pisa (Italy)

E-mail: Iorenzo.spada@sns.it; nicola.tasinato@sns.it smallest one within the pnicogen group, acting as pnicogen bond donor ${ }^{[12,15]}$. Because of the dual nature of nitrogen as pnicogen bond donor and more widely as bond acceptor (i.e., in hydrogen and halogen bonds), depending on the "chemical environment" to which it is bound, a number of interesting questions arises: 1) Is it possible to experimentally observe a complex showing the nitrogen-nitrogen noncovalent bond in the gas phase, i.e., without solvent or matrix effects that take place in liquid- or solid-state experiments, respectively? 2) What is the role played by that homo pnicogen noncovalent bond in competition with other noncovalent interactions? 3) Is the binding energy similar in magnitude to those typically observed for hydrogen bonds? 4) What is the key contribution (dispersions, electrostatics or polarization $^{[6,9 a, 11 a, 11 c, 16]}$ ) stabilizing the complex?

The opportunity to answer these questions is provided by joint experimental-theoretical investigations. Indeed, by combining the capability of rotational spectroscopy ${ }^{[17]}$ in supersonic expansion to unveil structural and dynamical details of weakly stabilized clusters in the gas phase with high-level quantum-chemical calculations, ${ }^{[18]}$ it is possible to unveil the nature of noncovalent interactions. In this respect, the simplest tertiary amine (trimethylamine, TMA) is a good candidate because the lack of $\mathrm{NH}$ bonds avoids any competition between putative pnicogen inter-molecular interactions and strong hydrogen bonds. At the same time, the negatively-charged nitrogen atom of TMA should lead to a stabilizing electrostatic interaction with the positively charged nitrogen of nitroethane (NE), whose low-energy NO antibonding orbitals should be also effective acceptors for the lone-pair electrons of the TMA nitrogen.

The starting point of this investigation was the exploration of the potential energy surface of the TMA - NE complex by using the B3LYP hybrid density functional ${ }^{[19]}$ in conjunction with the polarized double- $\zeta$ SNSD basis set, ${ }^{[20]}$ thus identifying three minima (M1, M2, M3, and M3' being equivalent to $M 3$ ) and the transition states ruling their interconversion (see Figure 1 for all structures along with the corresponding energies and labelings). All stationary point geometries were subsequently fully reoptimized at the B2PLYP-D3 ${ }^{[19,21]}$ level using the maug-cc-pVTZ$d \mathrm{H}$ basis set, ${ }^{[22]}$ also computing the corresponding harmonic force fields. Improved electronic energies were then obtained by means of the so-called "cheap" scheme defined in ref. [23], in which $\operatorname{ccSD}(T) / c c-p V T Z^{[24,25]}$ energies are corrected by core-valence and complete basis set extension contributions at the MP2 level. ${ }^{[26]}$ All interaction energies were then corrected for basis set superposition error $(\mathrm{BSSE})^{[27]}$ and for harmonic B2PLYP zeropoint energies (ZPEs). A full account of the computational details is given in the Supporting Information (SI). For all minima, the B2PLYP-D3/maug-cc-pVTZ- $d \mathrm{H}$ optimized geometries straightforwardly provided the equilibrium rotational constants 


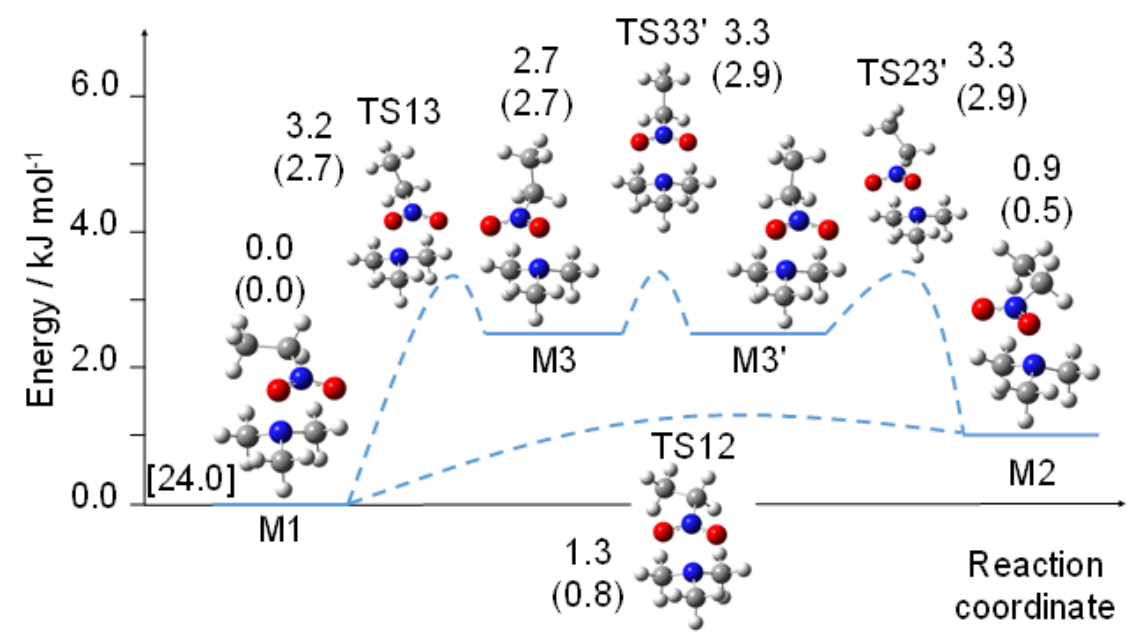

Figure 1. Potential energy surface of the TMA - NE complex showing the structures of the four minima (M1, M2, M3, M3') and the transition states governing their interconversion. The best-estimated relative electronic energies, also corrected by harmonic ZPE (within parentheses), are reported. The binding energy for the M1 isomer is reported in brackets.

$\left(B_{e}\right)$, then corrected for anharmonic vibrational effects ${ }^{[28]}$ at the B3LYP-D3/SNSD level in order to obtain the vibrational ground state rotational constants $\left(B_{0}\right)$. Furthermore, equilibrium dipole moments and nitrogen quadrupole-coupling constants were evaluated at the B2PLYP-D3/maug-cc-pVTZ- $d \mathrm{H}$ level as well. Guided by quantum-chemical calculations, the rotational spectrum for the 1:1 TMA-NE complex was recorded using a pulsed-jet Fourier-transform microwave (FTMW) spectrometer (as detailed in the Experimental Section) and assigned. The observed rotational transitions were fitted using the VMS-ROT program ${ }^{[29]}$ within the I' representation of Watson's $S$ reduction, ${ }^{[30]}$ also accounting for the quadrupole coupling due to the presence of two ${ }^{14} \mathrm{~N}$ nuclei (nuclear spin, $l=1$ ). Rotational transitions were labelled employing the quantum numbers resulting from the $F_{1}=I_{1}+J$ and $F=I_{2}+F_{1}$ coupling schemes, with $J$ being the rotational quantum number (as an example, the $505 \leftarrow 414$ rotational transition is shown in Figure 2, see also Figure S8.1 in the $\mathrm{SI}$ ).

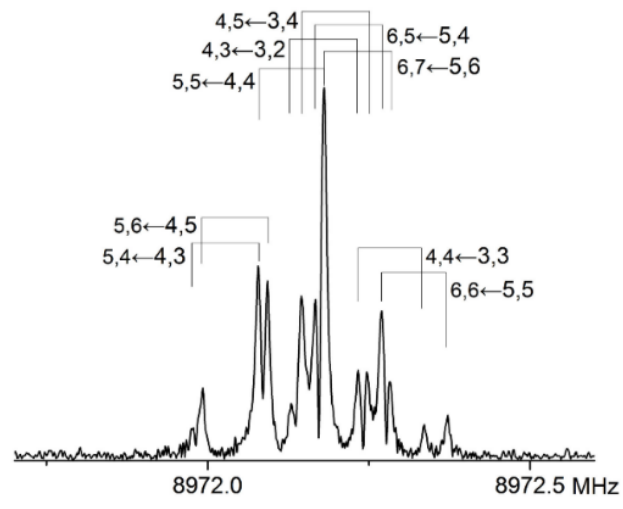

Figure 2. The $505 \leftarrow 414$ rotational transition showing the hyperfine structure due to the presence of two ${ }^{14} \mathrm{~N}$ nuclei. The labelling of the hyperfine components is $F_{1}^{\prime}, F^{\prime} \leftarrow F_{1}$ ", $F^{\prime \prime}$ (see text, for the coupling scheme).
The same procedure was followed for the molecular complex containing ${ }^{15} \mathrm{~N}-\mathrm{TMA}$ (i.e., $\left({ }^{15} \mathrm{~N}\right) \mathrm{TMA}-\left({ }^{14} \mathrm{~N}\right) \mathrm{NE}$ ), for which the quadrupole coupling interaction, resulting from the presence of only one ${ }^{14} \mathrm{~N}$ nucleus, was taken into account using the $F=I+J$ coupling scheme. The results are summarized in Table 1, while the assigned rotational transitions are reported in the SI.

Table 1. Experimental spectroscopic constants of the TMA-NE complexes, using Watson's S-reduction and Ir representation.

\begin{tabular}{|c|c|c|c|}
\hline \multicolumn{2}{|c|}{ Spectroscopic parameters } & $\left({ }^{14} \mathrm{~N}\right) \mathrm{TMA}-\left({ }^{14} \mathrm{~N}\right) \mathrm{NE}$ & $\left({ }^{15} \mathrm{~N}\right) \mathrm{TMA}-\left({ }^{14} \mathrm{~N}\right) \mathrm{NE}$ \\
\hline \multicolumn{2}{|c|}{$A[\mathrm{MHz}]$} & $1956.7717(1)^{[a]}$ & $1956.7625(5)$ \\
\hline \multicolumn{2}{|c|}{$B[\mathrm{MHz}]$} & $1035.08972(6)$ & $1030.25149(8)$ \\
\hline \multicolumn{2}{|c|}{$C[\mathrm{MHz}]$} & $902.83562(4)$ & $899.13798(5)$ \\
\hline \multicolumn{2}{|c|}{$D_{\lrcorner}[\mathrm{kHz}]$} & $0.5608(4)$ & $0.5527(8)$ \\
\hline \multicolumn{2}{|c|}{$D_{\mathrm{JK}}[\mathrm{kHz}]$} & $1.385(5)$ & $1.38(2)$ \\
\hline \multicolumn{2}{|c|}{$D_{\mathrm{K}}[\mathrm{kHz}]$} & $-1.77(1)$ & $-1.72(2)$ \\
\hline \multicolumn{2}{|c|}{$d_{1}[\mathrm{kHz}]$} & $-0.0772(2)$ & $-0.0732(4)$ \\
\hline \multirow{2}{*}{ TMA } & $X_{\text {aa }}[\mathrm{MHz}]$ & $-4.632(1)$ & - \\
\hline & $X_{\mathrm{bb}}-X_{\mathrm{cc}}[\mathrm{MHz}]$ & $-0.407(2)$ & - \\
\hline \multirow{2}{*}{ NE } & $X_{\text {аa }}[\mathrm{MHz}]$ & $1.039(3)$ & $1.037(5)$ \\
\hline & $X_{\mathrm{bb}}-X_{\mathrm{cc}}[\mathrm{MHz}]$ & $-0.866(3)$ & $-0.876(4)$ \\
\hline \multicolumn{2}{|c|}{$\sigma^{[\mathrm{b}]} / \mathrm{kHz}$} & 2.9 & 2.0 \\
\hline \multicolumn{2}{|l|}{$\mathrm{N}^{[c]}$} & 533 & 117 \\
\hline
\end{tabular}

[a] Standard errors within parenthesis are expressed in units of the last digit. Their values are obtained by using the PIFORM ${ }^{[31]}$ program. [b] Standard deviation of the fit. [c] Number of fitted transitions.

As a first point, the computed stability of the adduct with respect to the separate fragments $\left(24.0 \mathrm{~kJ} \cdot \mathrm{mol}^{-1}\right.$ for the M1 structure, as fully detailed in the $\mathrm{SI}$ ) is comparable to that of medium-strength hydrogen bonds. Next, the computed relative stabilities of the different energy minima shown in Figure 1 suggest that rotational transitions belonging to all three minima can be in principle 
observed. However, the very small energy barrier for relaxation to M1 (or M2) together with the corresponding small transition-state imaginary frequency (about $30 i \mathrm{~cm}^{-1}$ ) allow one to exclude isomer M3; this is furthermore confirmed by the comparison between experimental and calculated rotational parameters (see SI). On the other hand, it is hard to discriminate between M1 and M2. Indeed, their computed energy difference and also the energy barrier for their interconversion (TS12) are so small that a proper treatment of the physical-chemical parameters should involve vibrational averaging along the large amplitude motion connecting these three structures. While this investigation is currently under way in our laboratories, the present calculations are not able to discriminate whether M1 or the M1-TS12-M2 averaged structure corresponds to the single isomer experimentally observed. However, the similarity of the computed rotational constants for $\mathrm{M} 1$ and $\mathrm{M} 2$ as well as for their average (see SI) suggests that the present results are sufficiently reliable for guiding the experimental investigation and its interpretation. Even if an accurate and complete structural determination is challenging, small differences in the nitrogen-nitrogen interaction distance $\left(R_{\mathrm{NN}}\right.$, see Figure 3a for $\left.\mathrm{M} 1\right)$ can be noted when going from $\mathrm{M} 1$ $\left(R_{\mathrm{NN}}=3.044 \AA\right)$, to M1-TS12-M2 $\left(R_{\mathrm{NN}}=3.056 \AA\right)$ and to M2 $\left(R_{\mathrm{NN}}\right.$ $=3.081 \AA$ ), with the (NE)O-N $\cdots \mathrm{N}(\mathrm{TMA})$ angle being close to $90^{\circ}$ in all cases. This suggests a directional nitrogen-nitrogen interaction (see also Ref. [15b]), which is almost unaffected by the orientation of the methyl groups, this latter determining the M1, M1-TS12-M2 or M2 structural differences.

The stability of the observed adduct is clearly due to the presence of different noncovalent interactions, whose contributions have to be characterized at least at a semi-quantitative level, when aiming at providing useful information, for instance, for supramolecular design purposes. The nature of the inter-molecular interaction has been unraveled by means of an analysis based on the symmetry adapted perturbation theory $(\mathrm{SAPT})^{[32]}$ in conjunction with the aug-cc-pVDZ basis set. The results show that for M1, M2 and TS12 electrostatic and dispersion stabilizing interactions are comparable (about four times larger than induction) and larger than Pauli repulsion (see SI for details). Furthermore, we performed a detailed analysis of inter-molecular charge flows by means of the "Natural Orbital for Chemical Valence/ChargeDisplacement" (NOCV/CD) scheme ${ }^{[33]}$ (a full account is given in the $\mathrm{SI}$ ). In this model, the overall charge rearrangement issuing
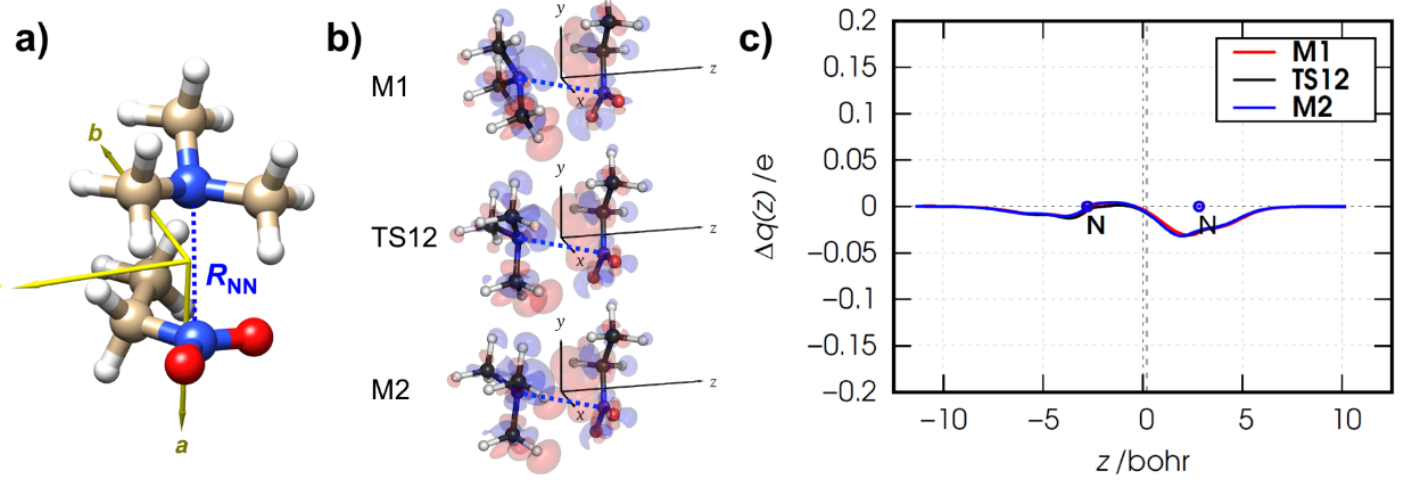

Figure 3. a) The M1 isomer showing the distance between nitrogen atoms $\left(R_{\mathrm{NN}}\right)$ in the principal axes of inertia system. This picture has been created using UCSF Chimera. ${ }^{[35]}$ b) Overall charge rearrangement $\Delta \rho(\mathrm{x}, \mathrm{y}, \mathrm{z})$ (isosurface $\left.\pm 0.0005\left(\mathrm{e} / \mathrm{bohr}^{3}\right)^{1 / 2}\right)$ for the M1,TS1 and M2 isomers of the TMA-NE complex. Volume regions in red indicate electron depletion, volume regions in blue indicate electron accumulation. c) Charge-rearrangement profile along the interaction axis $z$ upon bonding of TMA ( $\mathrm{N}$ on the left side) to NE ( $\mathrm{N}$ on the right side) 
Work is in progress in our laboratories to further elucidate the nature of the molecular adduct from both a structural and energetic point of view.

\section{Experimental Section}

A $0.5 \%$ mixture of ${ }^{14} \mathrm{~N}$-trimethylamine (or ${ }^{15} \mathrm{~N}$-trimethylamine) in helium at a stagnation pressure of 2 bar was streamed over nitroethane, kept at room temperature, and supersonically expanded through the solenoid valve (General Valve Series 9, nozzle diameter: $0.5 \mathrm{~mm}$ ) into a FabryPérot-type cavity. The rotational spectrum was recorded in the 6.5-18.5 $\mathrm{GHz}$ frequency region using a COBRA-type ${ }^{[37]}$ pulsed supersonic-jet Fourier-transform microwave (FTMW) spectrometer, ${ }^{[38]}$ described elsewhere. ${ }^{[39]}$ All rotational transitions are split by Doppler effect as a result of the coaxial arrangement of the supersonic jet and the resonator, rest frequencies thus being obtained as the arithmetic mean of the two Doppler components. The estimated accuracy of the frequency measurements is better than $3 \mathrm{kHz}$, and the resolution better than $7 \mathrm{kHz}$.

\section{Acknowledgements}

This work has been supported by MIUR "PRIN 2015" funds (Grant Number 2015F59J3R) and by the University of Bologna (RFO funds). The SMART@SNS Laboratory (http://smart.sns.it) is acknowledged for providing high-performance computer facilities. W.L. thanks the China Scholarship Council (CSC) for a Ph.D. grant. Support from the Italian MIUR (FIRB 2013 "Futuro in ricerca" - Protocol: RBFR132WSM) is also acknowledged.

Keywords: Pnicogen bond - Quantum Chemistry • Rotational Spectroscopy $\cdot$ Bond analysis $\cdot$ Intermolecular interactions

[1] E. A. Meyer, R. K. Castellano, F. Diederich, Angew. Chem. Int. Ed. 2003, 42, 1210-1250.

[2] S. E. Wheeler, T. J. Seguin, Y. Guan, A. C. Doney, Acc. Chem. Res. 2016, 49, 1061-1069.

[3] N. Vallavoju J. Sivaguru, Chem. Soc. Rev. 2014, 43, 4084-4101.

[4] X. Guo, Q. Liao, E. F. Manley, Z. Wu, Y. Wang, W. Wang, T. Yang, Y.-E. Shin, X. Cheng, Y. Liang, L. X. Chen, K.-J. Baeg, T. J. Marks, X. Guo, Chem. Mater. 2016, 28, 2449-2460.

[5] V. Georgakilas, J. N. Tiwari, K. C. Kemp, J. A. Perman, A. B. Bourlinos, K. S. Kim, R. Zboril, Chem. Rev. 2016, 116, 5464-5519.

[6] a) S. Scheiner, Acc. Chem. Res. 2013, 46, 280-288; b) S. Scheiner, Int. J. Quantum Chem. 2013, 113, 1609-1620.

[7] E. Arunan, G. R. Desiraju, R. A. Klein, J. Sadlej, S. Scheiner, I. Alkorta, D. C. Clary, R. H. Crabtree, J. J. Dannenberg, P. Hobza, H. G. Kjaergaard, A. C. Legon, B. Mennucci, D. J. Nesbitt, Pure Appl. Chem., 2011, 83, 1637-1641.

[8] G. R. Desiraju, P. S. Ho, L. Kloo, A. C. Legon, R. Marquardt, P. Metrangolo, P. Politzer, G. Resnati, K. Rissanen, Pure Appl. Chem. 2013 85, 1711-1713.

[9] a) A. Bauzá, D. Quiñonero, P. M. Deyà, A. Frontera, Phys. Chem. Chem. Phys. 2012, 14, 14061-14066; b) M. M. Watt, M. S. Collins, D. W. Johnson, Acc. Chem. Res. 2013, 46, 955-966; c) H. Schmidbaur, A. Schier, Organometallics 2008, 27, 2361-2395;

[10] a) S. Zahn, R. Frank, E. Hey-Hawkins, B. Kirchner, Chem. Eur. J. 2011, 17, 6034-6038; b) I. Alkorta, J. Elguero, S. J. Grabowski, Phys. Chem Chem. Phys. 2015, 17, 3261-3272; c) S. Bauer, S. Tschirschwitz, P. Lönnecke, R. Frank, B. Kirchner, M. L. Clarke, E. Hey-Hawkins, Eur. J. Inorg. Chem. 2009, 2776-2788. d) P. Kilian, A. M. Z. Slawin, J. D. Woollins, Chem. Eur. J. 2003, 9, 215-222.

[11] a) J. E. Del Bene, I. Alkorta, G. Sanchez-Sanz, J. Elguero, J. Phys. Chem. A 2011, 115, 13724-13731; b) I. Alkorta, G. Sanchez-Sanz, J. Elguero, J.
Phys. Chem. A 2012, 116, 9205-9213; c) S. Scheiner, J. Chem. Phys. 2011, 134, 094315; d) S. Tschirschwitz, P. Lonnecke, E. Hey-Hawkins Dalton Trans. 2007, 0, 1377-1382. e) J. E. Del Bene, I. Alkorta, G Sanchez-Sanz, J. Elguero, J. Phys. Chem. A 2012, 116, 3056-3060.

[12] A. Bauzá, R. Ramis, A. Frontera, J. Phys. Chem. A 2014, 118, 2827-2834.

[13] J. Schmauck, M. Breugst, Org. Biomol. Chem. 2017, 15, 8037-8045.

[14] a) J. S. Murray, P. Lane, T. Clark, K. E. Riley, P. Politzer, J. Mol. Model. 2012, 18, 541-548; b). P. Politzer, J. S. Murray, T. Clark, Phys. Chem. Chem. Phys. 2013, 15, 11178-11189; c) J. S. Murray, P. Politzer, WIREs Comput. Mol. Sci. 2017, 7, e1326.

[15] a) S. Scheiner, Chem. Phys. Lett. 2011, 514, 32-35. b) A. Bauzá, T. J. Mooibroek, A. Frontera, Chem. Commun. 2015, 51, 1491-1493.

[16] a) O. A. Stasyuk, R. Sedlak,C. Fonseca Guerra,' P. Hobza, J. Chem. Theory Comput. 2018, 14, 3440-3450; b) S. Scheiner, Phys. Chem. Chem. Phys., 2011, 13, 13860-13872; c) M. H. Kolár̆, P. Hobza, Chem. Rev. 2016, 116, 5155-5187.

[17] a) K. Müller-Dethlefs, P. Hobza, Chem. Rev. 2000, 100, 143-167; b) W. Caminati, J.-U. Grabow, Advancements in Microwave Spectroscopy in Frontiers and Advances in Molecular Spectroscopy, edited by Jaan Laane, Elsevier, 2018, pp. 569-598; c) M. Becucci, S. Melandri, Chem. Rev. 2016, 116, 5014-5037.

[18] C. Puzzarini, V. Barone, Acc. Chem. Res. 2018, 51, 548-556.

[19] a) A. D. Becke, J. Chem. Phys. 1993, 98, 5648-5652; b) J. P. Perdew, K. Burke, Y. Wang, Phys. Rev. B 1996, 54, 16533-16539.

[20] a) V.Barone, M.Biczysko, J.Bloino Phys. Chem. Chem. Phys 2014, 16, 1759-1787; b) http://dreamslab.sns.it/.

[21] S. Grimme, J. Chem. Phys. 2006, 124, 034108.

[22] E. Papajak, H. R. Leverentz, J. Zheng, D. G. Truhlar, J. Chem. Theory Comput. 2009, 5, 1197-1202.

[23] a) C. Puzzarini, M. Biczysko, V. Barone, L. Largo, I. Peña, C. Cabezas, J. L. Alonso, J. Phys. Chem. Lett. 2014, 5, 534-540. b) C. Puzzarini, M. Biczysko, J. Phys. Chem. A, 2015, 119, 5386-5395.

[24] a) G.D. Purvis III, R.J. Bartlett, J. Chem. Phys. 1982, 76, 1910-1918; b) K Raghavachari, G.W. Trucks, J.A. Pople, M. Head-Gordon, Chem. Phys. Lett. 1989, 157, 479-483.

[25] T.H. Dunning Jr., J. Chem. Phys. 1989, 90, 1007-1023.

[26] C. Møller, M.S. Plesset, Phys. Rev. 1934, 46, 618-622.

[27] S.F. Boys, F. Bernardi, Mol. Phys. 1970, 19, 553-566.

[28] D. Papoušek, M. R. Aliev, Molecular Vibrational-Rotational Spectra, Elsevier, Amsterdam, 1982.

[29] a) D. Licari, N. Tasinato, L. Spada, C. Puzzarini, V. Barone, J. Chem. Theory Comput. 2017, 13, 4382-4396; b) H. M. Pickett, J. Mol. Spectrosc 1991, 148, 371-377.

[30] J. K. G. Watson, in: J.R. Durig (Ed.), Vibrational Spectra and Structure, vol. 6, Elsevier, New York/Amsterdam, 1977, pp. 1-89.

[31] a) Z. Kisiel, PROSPE-Programs for ROtational SPEctroscopy. http://info.ifpan.edu.pl/ kisiel/prospe.htm. b) Z. Kisiel, in: J. Demaison et al. (Eds.), Spectroscopy from Space, Kluwer Academic Publishers, Dordrecht, 2001, pp.91-106

[32] B. Jeziorski, R. Moszynski, K. Szalewicz, Chem. Rev. 1994, 94, 1887 1930.

[33] a) G. Bistoni, S. Rampino, F. Tarantelli, L. Belpassi, J. Chem. Phys. 2015, 142, 084112; b) G. Bistoni, S. Rampino, N. Scafuri, G. Ciancaleoni, D Zuccaccia, L. Belpassi, F. Tarantelli, Chem. Sci. 2016, 7, 1174-1184; c) M. Fusè, I. Rimoldi, G. Facchetti, S. Rampino, V. Barone, Chem. Commun. 2018, 54, 2397-2400; d) A. Salvadori, M. Fusè, G. Mancini, S. Rampino, V. Barone, J. Comput. Chem. 2018, accepted on 18 June 2018.

[34] E. D. Glendening, C. R. Landis, F. Weinhold, WIREs Comput. Mol. Sci. 2012, 2, 1-42.

[35] E. F. Pettersen, T.D. Goddard, C.C. Huang, G. S. Couch, D. M. Greenblatt, E. C. Meng EC, T. E. Ferrin, J Comput Chem. 2004, 25,1605-1612.

[36] W. Caminati, J.-U. Grabow, Microwave spectroscopy: molecular systems, in Frontiers of Molecular Spectroscopy, Edited by Jaan Laane, Elsevier B. V. 2009, pp. 455-552.

[37] J.-U. Grabow, W. Stahl, H. Dreizler, Rev. Sci. Instrum. 1996, 67, 40724084.

[38] T.J. Balle, W.H. Flygare, Rev. Sci. Instrum. 1981, 52, 33-45.

[39] W. Caminati, A. Millemaggi, J.L. Alonso, A. Lesarri, J.C. Lopez, S. Mata, Chem. Phys. Lett. 2004, 392, 1-6. 
A gas-phase nitrogen-nitrogen noncovalent interaction has been unveiled in an environment free from solvent and matrix effects using rotational spectroscopy in supersonic expansion. This interaction largely prevails over the $\mathrm{C}-\mathrm{H} \cdots \mathrm{O}$ and $\mathrm{C}-\mathrm{H} \cdots \mathrm{N}$ hydrogen bonds as pointed out by different models for energy/charge partitioning. A SAPT analysis shows that electrostatic and dispersion interactions play a comparable role in stabilizing the complex.

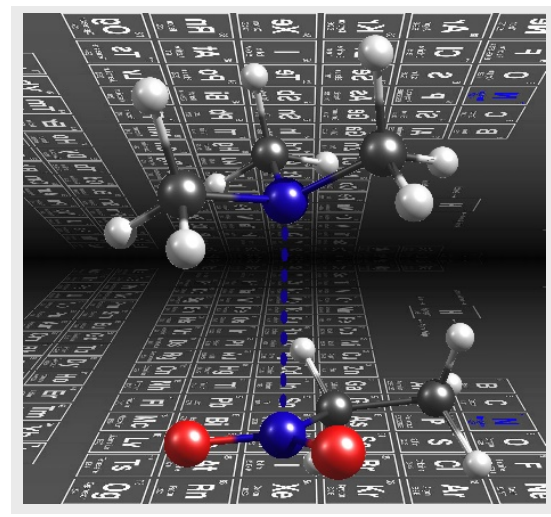

Weixing Li, Lorenzo Spada, ${ }^{*}$ Nicola Tasinato, ${ }^{*}$ Sergio Rampino, Luca Evangelisti, Andrea Gualandi, Pier Giorgio Cozzi, Sonia Melandri, Vincenzo Barone, Cristina Puzzarini*

Page No. - Page No.

Theory meets experiment for noncovalent complexes: the puzzling case of pnicogen interactions 